\title{
A IMAGEM EM ARTIGOS PUBLICADOS NO PERÍODO 1998-2007 NA ÁREA DE EDUCAÇÃO EM CIÊNCIAS
}

\author{
Lucia Helena Pralon de Souza* \\ Sheila Cristina Ribeiro Rego** \\ Guaracira Gouvêa***
}

RESUMO: Neste trabalho, procedemos à análise de um conjunto representativo dos artigos sobre imagens no campo da educação em ciências, publicado no período entre 1998 e 2007, com o objetivo de obter pistas sobre o status do corpo de conhecimentos sobre o tema construído até o momento. Utilizando as categorias: papel da imagem; natureza da imagem, suporte e mídia; abordagem; campo de estudos de referência; natureza do estudo; cenário dos estudos empíricos; instrumentos de coleta de dados e tipo de análise de dados, verificamos uma predominância dos campos de estudos da semiótica e da cognição, dos trabalhos empíricos sobre os teóricos e, ainda, uma preferência em abordar a imagem como objeto central de estudo e os aspectos de sua produção.

Palavras-chave: Imagem; Educação em Ciências; Pesquisa.

\section{IMAGE FROM THE VIEW OF PUBLISHED ARTICLES IN EDUCATION IN SCIENCE FIELD FROM 1998-2007}

ABSTRACT: This work analyses a set of representative articles about images in Science Education field, published from 1998 through 2007, with the aim of getting clues as to the status of the body of knowledge of the theme built so far. Using categories such as: image role; image nature; support and media; approach; reference studies scenery; empirical data collecting tools and kind of data analysis, we have noticed a predominance of the fields of semiotic and cognition, of the empiric works of the theorists and yet, a preference in approaching the image as the central study object and the aspects of its production.

Keywords: Image; Science Education; Investigation. 


\section{INTRODUÇÃO}

A crescente utilização da imagem no mundo moderno, impulsionada pelo desenvolvimento de técnicas cada vez mais complexas de produção, reprodução, transmissão, distribuição e recepção das imagens, tem criado uma necessidade de melhor compreender o papel das imagens em nossa relação com o mundo.

O processo de produção das imagens visuais passou por algumas modificações, desde as imagens registradas em pinturas em telas, fotografias, cinema, televisão, vídeo até as desenvolvidas por meio de linguagem computacional. Algumas características das formas de representação da realidade nesses veículos são discutidas por Dubois (1999), tendo em vista três questões: o maquinismo/ humanismo, a semelhança/dessemelhança e a materialidade/imaterialidade.

A primeira diz respeito ao papel da máquina na relação entre o real representado na imagem e o sujeito. Nessa relação, a máquina pode se limitar a captar a realidade ou ir além, registrando-a, possibilitando sua visualização e transmissão, e até transformando a concepção do que é a realidade. Os níveis de iconicidade da imagem, isto é, sua analogia com a realidade representada, são abordados por Dubois (1999) na questão da semelhança/dessemelhança, relacionada tanto ao espaço quanto ao tempo. Assim, a semelhança entre objeto e imagem diz respeito à interpretação do sujeito que cria a imagem, à reprodução e à difusão do movimento e à simulação da realidade. A materialidade/imaterialidade tem a ver com "o corpo da imagem", com a forma com que podemos entrar em contato com ela, com suas características sensíveis, como textura, cheiro e relevo.

Estudiosos da semiótica das imagens e da semiótica geral nos fornecem argumentos importantes para que possamos afirmar que é preciso aprender a ler imagens. Kress e van Leewen (1996, p. 2) consideram que a linguagem visual, sendo constituída por um sistema de representação simbólica, é influenciada pelas formas de representação e significação de uma determinada cultura. Consideram que "as estruturas visuais realizam sentidos assim como as linguísticas o fazem" e que, durante o processo de produção de uma imagem, a forma de representação assumida envolve escolhas que representam os interesses de quem a produziu e, consequentemente, envolve também posições ideológicas.

Para Joly (1996), vivemos numa civilização da imagem e não podemos escapar de utilizá-las, decifrá-las e interpretá-las o tempo todo. Essa impossibilidade de fuga pode fazer com que, às vezes, as imagens possam nos parecer ameaçadoras, colocando-nos no centro de um paradoxo interessante:

[...] por um lado, lemos as imagens de uma maneira que nos parece totalmente natural [...] por outro, temos a impressão de estar sofrendo de maneira mais inconsciente do que consciente a ciência de certos iniciados que conseguem nos "manipular", afogando-nos com imagens em códigos secretos que zombam de nossa ingenuidade (JOLY, 1996, p. 10). 
Entretanto a autora reconhece que esse paradoxo não se justifica inteiramente, pois essa leitura "natural" que fazemos das imagens só é possível porque "somos moldados da mesma massa que ela, a imagem nos é tão familiar e não somos cobaias, como às vezes acreditamos ser” (JOLY, 1996, p. 10). Somos, portanto, culturalmente iniciados na compreensão das imagens, e o reconhecimento disso nos possibilita aprofundar a análise e o entendimento dessa modalidade semiótica da comunicação humana.

A alfabetização na linguagem verbal é tema de pesquisa consolidado em vários campos de estudos, mundialmente, há muitos anos. Já a preocupação com as formas de leitura das imagens, seja no campo educacional ou da comunicação, e seu potencial para o aprendizado tem emergido de modo sistemático apenas mais recentemente.

Pesquisas têm sido realizadas na área de educação em ciências utilizando, em suas investigação, a imagem em textos didáticos. No Brasil, além da presença da imagem e sua função nos textos, são analisadas práticas de leitura das mensagens verbal e imagética nos livros didáticos de ciências (CHINCARO et al, 1999; MARTINS, 1997, 2001; MARTINS, GOUVÊAA \& PICCININI, 2005).

Trabalhos internacionais têm investigado, dentre outros aspectos, a relação entre texto e imagem (GOLDSMITH, 1987), a legibilidade das imagens no livro didático (KEARSEY \& TURNER, 1999), a organização do texto do livro didático por meio de diferentes formas de mensagens - verbal, matemática e imagética - (LEMKE, 1998) e as relações estabelecidas entre elas (KRESS et al, 1998).

Neste artigo, interessa-nos particularmente compreender sob quais olhares teóricos têm se desenvolvido as pesquisas em educação em ciências que abordam as imagens. Nosso objetivo é analisar um conjunto representativo dos estudos sobre imagens nesse campo que possa nos fornecer pistas sobre o status do corpo de conhecimentos sobre o tema até o momento.

\section{CONDUÇÃO DO ESTUDO}

Para investigar aspectos da forma como o tema imagem vem sendo abordado nas produções acadêmicas, foi realizado o levantamento dos artigos publicados no período entre 1998 e 2007 . Considerando os objetivos do presente estudo, escolhemos analisar artigos inicialmente pela possibilidade de acesso a esses textos e em segundo lugar porque é esperado que parte significativa das pesquisas acadêmicas sobre o tema em questão, e entre elas trabalhos de conclusão de curso (monografias, dissertações e teses), seja publicada em forma de artigos.

Optamos por pesquisar os artigos publicados a partir de 1998 devido ao início do estabelecimento formal da área de Ensino de Ciências no Brasil. Em 1997, ocorreu o primeiro Encontro Nacional de Pesquisa em Ensino de Ciências 
(Enpec), abrindo-se um espaço específico para divulgação dos estudos realizados nesse âmbito e para trocas de experiências entre os pesquisadores. No segundo Enpec, em 1999, a Associação Brasileira de Pesquisa em Educação em Ciências foi criada tendo por finalidade

[...] promover, divulgar e socializar a pesquisa em Educação em Ciências, através de encontros de pesquisa, escolas de formação para a pesquisa e publicações sobre pesquisa, bem como atuar como órgão representante da área junto a entidades nacionais e internacionais de educação, pesquisa e fomento (ABRAPEC, 2009).

A Coordenação de Aperfeiçoamento de Pessoal de Nível Superior (Capes), que, dentre outras atividades, realiza a avaliação da pós-graduação stricto sensu e promove o acesso e divulgação da produção científica, criou, em 2000, a área de Ensino de Ciências e Matemática. Com isso, foram aprovados cursos de mestrado (alguns destes, migrados da área de Educação) e estabelecidos critérios e padrões para a avaliação de qualidade da área.

Para avaliar a produção bibliográfica dos programas de pós-graduação stricto sensu nacionais, a Capes utiliza o Qualis ${ }^{1}$, materializado em uma listagem dos periódicos que divulgam os artigos provenientes desses programas, classificados por área. Até 2007, os periódicos eram avaliados segundo sua qualidade (alta, média ou baixa, respectivamente, com conceitos A, B e C) e seu âmbito de circulação (internacional, nacional ou local, respectivamente, I, N e L).

Como os periódicos classificados como $\mathrm{C}$ são considerados de pouco impacto acadêmico, este estudo se limitou a pesquisar os artigos de periódicos classificados como A ou B, que, em janeiro de 2008, totalizavam 103. O acesso aos periódicos se deu, primeiramente, através de busca pela internet. Quando não disponíveis em rede, foram procurados em duas bibliotecas. Achamos 74 dos periódicos listados (aproximadamente $72 \%$ ).

É importante observar que o foco do presente estudo é a imagem fixa, isto é, não fazem parte do levantamento aqui apresentado os artigos que se ocupavam apenas da imagem em movimento, como as imagens da televisão e de simulações computacionais. Toda imagem é marcada pela presença do espaço e do tempo, entretanto, as imagens que têm um suporte de registro material fixo (madeira, papel, pedra, tecido), diferentemente das imagens que trabalham com movimento real, são constituídas menos sob a influência do tempo do que do espaço (SANTAELLA \& NÖTH, 2008).

A distinção na materialidade e no desenvolvimento das imagens demanda formas de análise diferentes para as imagens fixas e móveis, parecendo, inicialmente, necessário limitar este estudo às imagens fixas, por terem sido, historicamente, as primeiras a surgir e por continuar fortemente presentes na sociedade, particularmente nos materiais de ensino. Uma vez que o presente estudo se refere apenas às imagens visuais ${ }^{2}$, alguns artigos que tratavam de imagens internas (mentais) foram descartados da análise. 
O Quadro 1 apresenta a quantidade de revistas consultadas e artigos encontrados.

Quadro 1: Levantamento dos artigos

\begin{tabular}{c|c|c|c|c} 
Nivel & Circulação & $\begin{array}{c}\text { Revistas } \\
\text { consultadas }\end{array}$ & $\begin{array}{c}\text { Revistas com artigos } \\
\text { sobre o tema }\end{array}$ & $\begin{array}{c}\text { Artigos } \\
\text { encontrados }\end{array}$ \\
\hline A & Internacional & 11 & 6 & 21 \\
& Nacional & 12 & 5 & 14 \\
& Local & 1 & 0 & 0 \\
\hline Subtotal & & 24 & 11 & 35 \\
\hline B & Internacional & 7 & 1 & 7 \\
& Nacional & 34 & 5 & 3 \\
\hline Subtotal & Local & 9 & 3 & 12 \\
\hline TOTAL & & 50 & 9 & $\mathbf{4 7}$
\end{tabular}

Para encontrar os artigos que tratavam do tema imagem, decidimos analisar os seus títulos por palavras-chave, como imagem, desenho e fotografia. Entretanto, este método se mostrou ineficaz porque vários artigos que abordavam o assunto estavam sendo deixados de lado por não conterem estas palavras no título. Assim, resolvemos ler todos os títulos. As palavras que nos indicaram relevância dos artigos para o estudo foram: imagem(ns), representação(ões), visual(is), ilustração(ões), gráfico(s), desenho(s), quadrinho(s), tirinhas, foto(s), fotografia(s).

A partir da leitura prévia de 6 artigos escolhidos aleatoriamente, construímos as categorias em que foram analisados: (a) papel da imagem; (b) natureza da imagem, suporte e mídia; (c) abordagem; (d) campo de estudos de referência; (e) natureza do estudo; (f) cenário dos estudos empíricos; (g) instrumentos de coleta de dados; e (h) tipo de análise de dados. Essas categorias serão detalhadas ao longo da análise dos dados. Ao observar a escassez de informações apresentadas nos resumos dos artigos em relação às categorias definidas, mostrou-se necessária a leitura integral dos 47 artigos encontrados. A seguir, examinamos as definições adotadas para cada uma dessas categorias, assim como os resultados obtidos.

\section{ANÁLISE DOS DADOS}

\section{Papel da imagem no artigo}

O primeiro ponto a chamar nossa atenção foi a função da imagem no artigo, isto é, se ela era o objeto de estudo ou um recurso para problematizar outras questões. Dos 47 artigos, em 34 (72,3\%) a imagem foi tratada como o objeto da pesquisa, enquanto em $13(27,7 \%)$ ela foi utilizada para ajudar na compreensão de diferentes assuntos, como aspectos culturais em livros didáticos 
(MACEDO, 2004; SILVA \& CAVASSAN, 2005), concepções alternativas de estudantes (AGUILAR et al, 2007) e desenvolvimento de estratégias pedagógicas para o aprendizado (COSTA et al, 2006).

Os números encontrados parecem demonstrar uma preocupação acadêmica em construir os alicerces do estudo teórico da imagem na área da Educação, o que é necessário para uma utilização mais consistente da imagem como ferramenta na pesquisa de diferentes temas e para seu uso no ensino.

\section{Natureza da imagem, suporte e mídia}

A natureza da imagem diz respeito ao fato de o artigo abordar somente imagem fixa ou, juntamente com esta, a imagem em movimento.

Chamamos de suporte ao meio material onde a imagem é produzida ou reproduzida (papel, tela, acetato, couro, fita magnética, meio digital). A mídia é o objeto cultural que veicula a imagem (livro didático, TV, jornal, revista, computador, gravura, cartaz, folheto, panfleto, etc.). O Quadro 2 apresenta o resumo da análise dessa categoria.

Quadro 2: Natureza da imagem, suporte e mídia

\begin{tabular}{|c|c|c|c|c|c|}
\hline Tipo de imagem & $\left|\begin{array}{c}\text { Total de } \\
\text { artigos }\end{array}\right|$ & Suporte & $\begin{array}{c}\text { Total de } \\
\text { artigos }\end{array} \mid$ & Mídia & $\begin{array}{c}\text { Total de } \\
\text { artigos }\end{array}$ \\
\hline Imagem fixa & 37 & $\begin{array}{c}\text { Papel } \\
\text { Tela } \\
\text { Fotografia digital }\end{array}$ & $\begin{array}{c}31 \\
1 \\
2\end{array}$ & $\begin{array}{c}\text { Livros didáticos } \\
\text { Apostilas } \\
\text { Revistas de divulgação } \\
\text { Fotos } \\
\text { Tirinhas } \\
\text { Testes } \\
\text { Desenhos (alunos e profs.) }\end{array}$ & $\begin{array}{c}22 \\
2 \\
1 \\
2 \\
3 \\
1 \\
4\end{array}$ \\
\hline Imagem fixa e em movimento & 10 & $\begin{array}{c}\text { Papel } \\
\text { Meio digital } \\
\text { Meio magnético (VHS) } \\
\text { Acetato }\end{array}$ & $\begin{array}{l}4 \\
5 \\
2 \\
1\end{array}$ & $\begin{array}{c}\text { Gravuras } \\
\text { Livro didático } \\
\text { Revistas de divulgação } \\
\text { Softwares } \\
\text { Vídeos } \\
\text { TV }\end{array}$ & $\begin{array}{l}1 \\
3 \\
1 \\
3 \\
3 \\
2\end{array}$ \\
\hline
\end{tabular}

Pela própria delimitação do estudo, a maioria dos artigos (37) tratava da imagem fixa. Além disso, como os artigos são oriundos de periódicos da área do Ensino de Ciências e Matemática, e o principal instrumento didático é o livro (JIMÉNEZ \& PERALES, 2001; CHOPPIN, 2004), era esperada uma predominância dessa mídia (25 artigos) e, consequentemente, do suporte papel (35). Convém observar a presença de três artigos que, apesar de limitarem seus estudos às imagens fixas, não deixam claro o tipo de suporte e mídia analisados. Outros tratam de mais de uma mídia na mesma pesquisa. 


\section{Abordagem}

Refere-se a dois momentos na comunicação de uma mensagem: o da sua produção e o do seu consumo. Hall (2003), ao discorrer sobre a codificação e a decodificação da mensagem televisiva, trata a produção e o consumo como momentos diferentes, porém articulados. Sendo a produção o momento de construção da mensagem, consideramos como artigos que abordam esse aspecto aqueles que se referiam às diferentes técnicas de produção de imagens, seus aspectos composicionais e as leituras preferenciais, isto é, o significado da imagem pensado pelo seu autor e/ou editor.

O consumo está relacionado à tradução da imagem por parte de quem a lê, isto é, ao sentido dado a ela por parte de quem a recebe. Assim, os artigos sobre o consumo da imagem foram identificados como os que abordavam a análise de leituras de imagens realizadas efetivamente por alunos, professores ou quaisquer outros sujeitos e os efeitos dessa leitura na construção de sentido e na aprendizagem em geral. Relativamente a estes aspectos (produção e consumo) encontramos, respectivamente, 31 e 11 artigos. Apenas em cinco estudos, a produção e o consumo foram abordados de forma conjunta.

À primeira vista, o resultado da análise desta categoria poderia parecer evidente, uma vez que apenas $27,7 \%$ dos artigos adotavam a imagem como recurso, o que indicaria a análise de seu consumo. Entretanto, um exame mais cuidadoso dos dados revelou a predominância da imagem como objeto de estudo, tanto nos estudos que tratavam de sua produção quanto de seu consumo. Apenas nos cinco artigos que estudavam simultaneamente a produção e o consumo da imagem houve uma predominância do papel da imagem como recurso para a pesquisa de outros assuntos.

\section{Campo de estudos de referência}

A identificação dos referenciais teóricos adotados pelos autores dos artigos analisados em nosso estudo baseou-se, preferencialmente, no anúncio do próprio autor, ou seja, na filiação teórica assumida explicitamente no artigo. Quando isso não acontecia, a identificação se deu a partir de nossas inferências sobre o conteúdo do artigo. A partir destes critérios passamos a considerar os seguintes campos, definidos a partir de referências da área:

Estudos da semiótica: de acordo com Santaella (1985, p. 15), investigam "todas as linguagens possíveis, ou seja, [...] os modos de constituição de todo e qualquer fenômeno de produção de significação e de sentido".

Estudos da cognição: consideramos que, de modo geral, trata-se daqueles que buscam compreender o modo como as pessoas pensam, interpretam, percebem e representam o mundo (NEVES, 2006).

Estudos da didática: podem ser entendidos como aqueles que se ocupam da "reflexão sistemática e busca de alternativas para os problemas da prática pedagógica” (CANDAU, 1993, p. 12). 
Estudos da cultura: dentro de uma perspectiva histórico-antropológica em que a cultura é considera como "a maneira pela qual os humanos se humanizam por meio de práticas que criam a existência social, econômica, política, religiosa, intelectual e artística" (CHAUí, 2000. p. 7), são aqueles que buscam analisar justamente essas práticas de humanização.

Estudos da epistemologia: preocupam-se com os processos pelos quais o conhecimento é produzido e adquirido, em que se fundamenta tal conhecimento e quais as coisas que podem ou não ser conhecidas (CHIBENI, 2009).

Estudos do currículo: aqueles que abarcam

[...] planos e propostas (currículo formal), o que de fato acontece nas escolas e nas salas de aula (currículo em ação), bem como as regras e as normas não explicitadas que governam as relações que se estabelecem nas salas de aula (currículo oculto) (MOREIRA, 1997. p. 15).

Uma abordagem conjunta destas três dimensões caracteriza um "currículo concebido como texto, como um instrumento privilegiado de construção de identidades e subjetividades" (MOREIRA, 1997, p. 15).

Estudos da arte: envolvem "estudos das diversas manifestações artísticas em suas expressões erudita e popular, sacra e profana, rural e urbana, utilizando os recursos teóricos metodológicos das Ciências Sociais, Comunicação e Educação" (Sociedade Científica de Estudos da Arte, 2008. Seção: Quem somos).

Estudos históricos: de acordo com Barros (2004)

[...] apesar de falarmos freqüentemente em uma "História Econômica", em uma "História Política", em uma "História Cultural", e assim por diante, a verdade é que não existem fatos que sejam exclusivamente econômicos, políticos ou culturais. Todas as dimensões da realidade social interagem, ou rigorosamente sequer existem como dimensões separadas. Mas o ser humano, em sua ânsia de [...] compreender melhor o mundo, acaba sendo obrigado a proceder a recortes e a operações simplificadoras, e é neste sentido que devem ser considerados os compartimentos que foram criados pelos próprios historiadores para enquadrar os seus vários tipos de estudos históricos (BARROS, 2004, p. 15).

Nesse sentido, em nosso estudo, referimo-nos especificamente aos estudos da História da Cultura Material, cujo objeto é a imagem científica.

Estudos da comunicação: tratam da "criação, produção, distribuição, recepção e análise crítica referentes às mídias, às práticas profissionais e relacionadas com estas, e a suas inserções culturais, políticas e econômicas" (Diretrizes Curriculares da Área de Comunicação e Suas Habilitações. p. 5).

Estudos etnográficos: para Mattos (2001) os trabalhos etnográficos compreendem 
[...] o estudo, pela observação direta e por um período de tempo, das formas costumeiras de viver de um grupo particular de pessoas: um grupo de pessoas associadas de alguma maneira, uma unidade social representativa para estudo, seja ela formada por poucos ou muitos elementos. Por exemplo: uma vila, uma escola, um hospital, etc. (MATTOS, 2001, p. 16).

O resultado dessa análise pode ser visto no Quadro 3, onde podemos perceber o predomínio dos estudos referenciados nos campos da semiótica e da cognição sobre os outros campos. Entretanto, como estes campos de estudo não são excludentes, encontramos 10 artigos com bases teóricas referenciadas em mais de um campo simultaneamente, conforme demonstra o Quadro 4:

Quadro 3: Referencial teórico

\begin{tabular}{c|c|c} 
& Campos de estudos & Número de artigos \\
\hline $\mathbf{1}$ & Estudos da semiótica & 19 \\
\hline $\mathbf{2}$ & Estudos da cognição & 17 \\
\hline $\mathbf{3}$ & Estudos da didática & 6 \\
\hline $\mathbf{4}$ & Estudos da cultura & 5 \\
\hline $\mathbf{5}$ & Estudos da epistemologia & 3 \\
\hline $\mathbf{6}$ & Estudos do currículo & 2 \\
\hline $\mathbf{7}$ & Estudos da arte & 2 \\
\hline $\mathbf{8}$ & Estudos históricos & 2 \\
\hline $\mathbf{9}$ & Estudos da comunicação & 1 \\
\hline $\mathbf{1 0}$ & Estudos etnográficos & 1
\end{tabular}

Quadro 4: Artigos fundamentados em mais de um referencial teórico

\begin{tabular}{c|c} 
Campos de estudos & Número de artigos \\
\hline Estudos da semiótica e cognição & 5 \\
\hline Estudos da semiótica e epistemologia & 2 \\
\hline Estudos da semiótica, cognição e didática & 1 \\
\hline Estudos culturais e da semiótica & 1 \\
\hline Estudos culturais e da arte & 1 \\
\hline Estudos culturais e da cognição & 1
\end{tabular}

Se considerarmos que na maioria dos estudos analisados $(70 \%)$ a imagem desempenha o papel de principal objeto de estudo, não poderíamos esperar um resultado diferente, pois o campo da semiótica é referência para estudos que buscam compreender a linguagem das imagens. $\mathrm{O}$ mesmo se pode dizer sobre a recorrência dos estudos referenciados no campo da cognição, já que estudar as linguagens envolve, necessariamente, analisar produção de significação e de sentido. Essa afinidade também justifica o número de artigos (cinco) que adotam os campos da semiótica e da cognição simultaneamente (Quadro 4).

\section{Natureza do estudo}

Os estudos foram classificados, quanto à sua natureza, como empíricos ou teóricos. Os primeiros, para refletirem sobre determinado tema, lançam mão 
de levantamentos de dados retirados da experiência em campo, com a presença ou não de sujeitos. Como artigos teóricos, foram definidos aqueles que apresentavam uma discussão conceitual sem, para isso, respaldarem-se em um levantamento ou análise de dados empíricos.

Dos 47 artigos, 16 (34\%) são teóricos e 31 (66\%) empíricos. Isso demonstra uma necessidade ou preferência em discutir temas relativos ao ensino baseados em elementos provenientes da experiência educacional.

\section{Cenário dos estudos empíricos}

Esta categoria contempla apenas os 31 artigos empíricos e é subdividida em: contexto, nível de ensino, disciplina de referência, tema e sujeitos. Em relação ao contexto, nenhum deles se referia a outro contexto diferente do escolar.

O nível de ensino diz respeito às etapas da educação formal no Brasil (Fundamental, Médio e Superior), sendo preciso fazer sua correspondência com as classificações de outros países para os estudos realizados em sistemas educacionais diferentes do nosso. Os resultados da análise das categorias nivel de ensino, disciplina de referência e tema são expostos no Quadro 5.

Pode-se observar, no Quadro 5, a carência de estudos que abordem a imagem no nível superior, a inexistência da Matemática e a pouca presença da Química nos periódicos examinados, a diversidade de temas e a falta de informações ao se indicar algumas características das pesquisas realizadas.

Quadro 5: Nível de ensino, disciplina de referência e tema

\begin{tabular}{|c|c|c|c|}
\hline Nível de ensino & Disciplina & Tema & Total de artigos \\
\hline \multirow[t]{10}{*}{ Fundamental (10) } & Ciências & Astronomia & 1 \\
\hline & & Digestão e excreção & 1 \\
\hline & & Geologia e geociências & 1 \\
\hline & & Botânica & 1 \\
\hline & & Educação ambiental & 1 \\
\hline & & Não especifica & 1 \\
\hline & Ciência e Português & Geociências & 1 \\
\hline & Português & Não especifica & 1 \\
\hline & Não especifica & Energia elétrica & 1 \\
\hline & & Não especifica & 1 \\
\hline Fundamental e Médio (1) & Não especifica & Não especifica & 1 \\
\hline \multirow[t]{5}{*}{ Médio (8) } & Biologia & Não especifica & 2 \\
\hline & Física & Mecânica & 1 \\
\hline & & Oscilações & 1 \\
\hline & Física e Química & Mecânica & 2 \\
\hline & Não especifica & Biossegurança & 2 \\
\hline \multirow[t]{2}{*}{ Médio e Superior (3) } & Física & Não especifica & 2 \\
\hline & Química & Gases e reações químicas & 1 \\
\hline \multirow[t]{2}{*}{ Superior (3) } & Biologia & Células & 1 \\
\hline & Física & Mecânica & 2 \\
\hline Fundamental, Médio e Superior (1) & Biologia & Gene e cromossomo & 1 \\
\hline \multirow{4}{*}{ Não especifica (5) } & Física & Óptica & 1 \\
\hline & & Não especifica & 1 \\
\hline & Não especifica & Tecnologia & 1 \\
\hline & & Não especifica & 2 \\
\hline
\end{tabular}


Em 52\% dos estudos empíricos (16), verificou-se a ausência de sujeitos, por serem conduzidos apenas pela análise de material. Os estudantes e professores estiveram presentes como sujeitos, respectivamente, em 11 e dois artigos. Utilizaram-se estudantes e professores juntos na realização de duas pesquisas.

\section{Instrumentos de coletas de dados}

Verificamos que o instrumento mais utilizado para coletar os dados foi a análise de material, que consta em 28 artigos (Quadro 6); destes, mais da metade (15) voltada para o livro didático. O questionário também é presença marcante na coleta de dados. Alguns estudos utilizaram mais de um instrumento, fazendo com que o total de artigos no Quadro 6 exceda a quantidade de estudos empíricos (31).

Quadro 6: Instrumentos de coleta de dados

\begin{tabular}{|c|c|c|}
\hline Instrumento & \multicolumn{2}{|l|}{ Quantidade de artigos } \\
\hline Não especificado & \multicolumn{2}{|l|}{1} \\
\hline Grupo focal & \multicolumn{2}{|l|}{1} \\
\hline Entrevista & \multicolumn{2}{|l|}{4} \\
\hline Questionário & \multicolumn{2}{|l|}{10} \\
\hline \multirow[t]{7}{*}{ Análise de material } & Livro didático & 15 \\
\hline & Material produzido pelos sujeitos & 5 \\
\hline & Apostilas & 1 \\
\hline & Vídeo & 2 \\
\hline & Fotos & 3 \\
\hline & Softwares educativos & 1 \\
\hline & Revistas & 1 \\
\hline
\end{tabular}

\section{Tipo de análise de dados}

Para o levantamento desta categoria, consideramos, primeiramente, a referência adotada explicitamente pelo(s) autor(es) no artigo para realizar a análise de seus dados. Caso não houvesse uma referência explícita, inferimos que a análise tenha se baseado em uma categorização criada pelo(s) autor(es) a partir dos dados empíricos.

Dos 31 artigos empíricos, verificamos que 21 (68\%) não mencionaram um referencial específico adotado na análise de seus dados. Os 10 artigos restantes distribuem-se nos seguintes referenciais: (a) análise de discurso; (b) análise de conteúdo; (c) análise multirreferencial; (d) análise de níveis de processamento de informação; (e) análise fatorial de correspondências múltiplas e classificação sobre coordenadas fatoriais; (f) análise sequencial; e (g) análise com base no enfoque cultural.

O resultado obtido parece demonstrar que não existe um referencial privilegiado para a análise de dados relacionados à produção e ao consumo das imagens. Pelo contrário, parecemos viver um momento de preocupação/necessidade de criação de categorias de análise baseada na experiência empírica. 


\section{CONCLUSÕES}

Vale destacar algumas dificuldades encontradas para a realização desse levantamento. Foi preciso analisar os textos completos dos artigos porque os títulos, resumos e palavras-chave apresentados não continham as informações que precisávamos categorizar. Apesar da facilidade que a internet proporciona de acesso aos periódicos, alguns sites não foram encontrados e outros não disponibilizavam os artigos completos. Vários estudos não se comprometiam explicitamente com um referencial teórico, nem mencionavam filiação a um campo de estudos de referência.

O levantamento desenvolvido no presente estudo evidenciou algumas características predominantes nas publicações sobre o tema imagem na área do Ensino de Ciências. Primeiramente, pudemos observar um aumento significativo da produção intelectual sobre o tema ao longo do período investigado: dos 47 artigos analisados, 30 (63,8\%) foram publicados de 2004 a 2007.

Verificamos que grande parte dos artigos aborda a imagem como objeto central de estudo e não como recurso na investigação de outras questões. Além disso, muitos artigos abordam a produção da imagem e não as formas de leituras efetivamente realizadas da mensagem imagética. Em nosso entendimento isso demonstra que ainda vivemos um momento de consolidação teórica da área. Os estudos de produção da imagem precedem os estudos da leitura e os da leitura são importantes porque envolvem a questão do aprendizado no ensino de ciências. A ampliação dos trabalhos que envolvam leitura poderá gerar e consolidar intervenções na sala de aula.

Nos estudos empíricos (que apresentaram uma frequência maior que os teóricos), verificamos que a pesquisa é majoritariamente direcionada para a educação básica, havendo poucos estudos com foco no Ensino Superior. Em relação à disciplina de referência, verificamos a presença marcante das Ciências (no Ensino Fundamental) e da Física (no Ensino Médio), esta última abordando mais a área da Mecânica, revelando uma participação predominante da comunidade de Física neste campo de pesquisa.

Para a análise dos dados, estes estudos empíricos utilizam, em geral, categorias próprias elaboradas a partir dos dados coletados, poucos se valem de referencial teórico específico. Isso sugere uma preocupação/necessidade de criação de categorias de análise baseada na experiência empírica.

Tanto nos artigos de natureza teórica quanto nos empíricos, percebemos uma predominância da utilização dos campos de estudos da semiótica e da cognição, refletindo escolhas do campo da Educação em Ciências no período estudado. Inicialmente, consideramos que a imagem poderia ser tratada como objeto de pesquisa em qualquer campo de referência, mas, após a análise dos dados, acompanhada de uma reflexão teórica sobre a questão, pareceu-nos que apenas os artigos baseados nos estudos da semiótica poderiam tratar a imagem como objeto, uma vez que o tema dessa ciência é o estudo das linguagens, incluindo, portanto, a linguagem imagética. 
Entretanto, os estudos no campo da cognição também utilizam os conceitos de signo e de representação para entender as representações mentais, e estas sempre têm origem, de alguma forma, nas imagens visuais (SANTAELLA $\&$ NÖTH, 2008). O que justifica o tratamento da imagem como objeto de estudo nesse campo. Afinal, como afirma Bakhtin (p. 35, 1986), "a consciência adquire forma e existência nos signos criados por um grupo organizado no curso de suas relações sociais".

Uma vez que o tema imagem passa, atualmente, por uma formação teórica, consideramos importante que os artigos apresentem sua filiação com um campo de estudos de forma explícita, indicando as concepções teóricas mais utilizadas na condução das pesquisas.

Finalmente, consideramos que a existência de grupos no campo da Educação em Ciências voltados para o estudo das imagens revela que tal perspectiva é um tema importante nos processos de aprendizagem em ciências. Não podemos negligenciar as imagens nessa aprendizagem. Nesse sentido, como possibilidade de desdobramentos para a área, sinalizamos a necessidade de as investigações irem além do Ensino Fundamental e Médio e envolverem outras disciplinas científicas ou áreas da ciência. Além disso, é preciso uma maior quantidade de trabalhos que abordem outros materiais além do livro didático, e que envolvam sujeitos, como os professores que leem imagens e são responsáveis pela escolha do material didático. Como visto, $52 \%$ dos estudos empíricos tratam apenas da análise de material, não havendo, portanto, a participação de sujeitos. Os 48\% restantes envolvem principalmente estudantes e somente quatro artigos tratam de leitura de imagens por professores. 


\section{NOTAS}

1 "Qualis é o conjunto de procedimentos utilizados pela Capes para estratificação da qualidade da produção intelectual dos programas de pós-graduação." < http://qualis.capes.gov.br/webqualis/.>

2 De acordo com Martine Joly (1996) a semiologia da imagem surgiu em meados do século XX apegada essencialmente ao estudo das mensagens visuais. Nesse sentido, a imagem tornou-se portanto sinônimo de "representação visual" (p. 37).

\section{REFERÊNCIAS BIBLIOGRÁFICAS}

ABRAPEC. Associação Brasileira de Pesquisa e Educação em Ciências. Disponível em <http://www.fae.ufmg.br/abrapec>. Acesso em: 03 fev. 2009.

AGUILAR, S.; MATURANO, C. \& NÚNEZ, G. Utilización de imágenes para la detección de concepciones alternativas: um estudio exploratório com estudiantes universitários. Revista Electrónica de Enseñanza de las Ciencias, v. 6, n. 3, p. 691-713, 2007. Disponível em: <http://www.saum.uvigo.es/reec/volumenes/volumen6/ART12_Vol6_N3.pdf>. Acesso em: 20 fev. 2008.

BAKHTIN, Mikhail M. (VOLOCHINOV). Marxismo e filosofia da linguagem. São Paulo: Editora Hucitec, 1986.

BARROS, José D’Assunção. O campo da história: especialidades e abordagens. 2. ed. Petrópolis: Vozes, 2004.

CANDAU, V. M. (org.). A didática em questão. 11. ed. Petrópolis: Vozes, 1993.

CHAUÍ, Marilena. Convite à Filosofia. In: Unid. 8, Cap. 1. São Paulo: Ática, 2000. Disponível em: <http://br.geocities.com/mcrost02/index.htm>. Acesso em: 31 jan. 2009.

CHIBENI, S.S. Epistemologia: noções introdutórias. Disponível em: $<$ http://www.unicamp.br/ chibeni/texdid/epistemologia.htm>. Acesso em: 15 fev. 2009.

CHINCARO, A.; FREITAS, C. \& MARTINS, I. Tipos e funções de imagens em livros didáticos de Ciências. In: Encontro de Pesquisa em Educação em Ciências, 2, 1999. São Paulo. Atas do II Encontro de Pesquisa em Educacão em Ciências. São Paulo: ENCI, 1999. 1 CD-ROM.

CHOPPIN, A. História dos livros e das edições didáticas: sobre o estado da arte. Educ. Pesqui., v. 30, n. 3, set-dez, 2004, p. 549-566.

COSTA, M. A. F.; COSTA, M. F. B.; LIMA, M. C. A. B.; et al. O desenho como estratégia pedagógica no ensino de ciências: o caso da biossegurança. Revista Electrónica de Enseñanz̧a de las Ciencias, v. 5, n. 1, 2006. Disponível em: <http://www.saum.uvigo.es/reec/volumenes/ volumen5/ART10_Vol5_N1.pdf>. Acesso em: 20 fev. 2008.

Diretrizes curriculares da área de Comunicaşão e suas habilitações. <Disponível em: http://www.enecos.org.br/docs/diretrizes.doc>. Acesso em: 15 fev. 2009.

DUBOIS, Philippe. A linha geral (as máquinas de imagens). Cadernos de Antropologia e Imagem, Rio de Janeiro, v. 9, n. 2, 1999, p. 65-85.

GOLDSMITH, E. The analysis of illustration in theory and practice. In: Willows, D. M.; Houghton, H. A. (eds.). The psychology of illustration: II Instructional Texts. New York: Springer Verlag, 1987, p. 53-85.

HALL, S. Da diáspora: identidades e mediações culturais. Belo Horizonte: Editora UFMG, 2003. 410p.

JIMÉNEZ, J. D. \& PERALES, F. J. Aplicación del análisis secuencial al estudio del texto escrito e ilustraciones de los libros de física y química de la ESO. Revista Ensenanza de las Ciencias, v. 19, n. 1, 2001.

JOLY, Martine. Introducão à análise da imagem. Campinas: Papirus, 1996 - (Coleção Ofício de Arte e Forma). KEARSEY, J.; TURNER, S. How useful are the figures in school biology textbooks? Journal of Biological Education, v. 33 (2), 1999, p. 87-94.

KRESS, G.; OGBORN. J.; MARTINS, I. A. Satellite View of Language: some lessons from science classrooms. Language Awareness, v. 7, n. 2/3, 1998, p. 69-89. 
KRESS, G. \& VAN LEEUWEN, T. Reading images: the Grammar of visual design. London: Routledge, 1996.

LEMKE, J. Multiplying meaning: visual and verbal semiotics in scientific texts. In: MARTIN, J. R. \& VEEL, R. (eds.). Reading Science. London: Routledge, 1998.

MACEDO, E. A imagem da ciência: folheando um livro didático. Educação \& Sociedade, Campinas, v. 25 , n. 86 , abr. 2004 , p. $103-129$.

MARTINS, I. O papel das representações visuais no ensino e na aprendizagem de ciências. In: Encontro de Pesquisa e Educação em Ciências, 1, 1997. Águas de Lindoia. Atas do I Encontro de Pesquisa e Educação em Ciências. Águas de Lindoia: ENCI, 1997, p. 294-299.

MARTINS, I. Visual imagery in school science texts. In: Graesser, A.; Otero, J. \& De Leon, J. A. (eds.). The Psychology of Scientific Text Comprehension. Hillsale, N J: Larence Erlbaum Associate Publishers, 2001.

MARTINS, Isabel; GOUVEA, Guaracira; PICCININI, Cláudia. Aprendendo com imagens. Ciência e Cultura, Campinas, v. 57, n. 4, 2005, p. 38-40.

MATTOS, C. L. G. A abordagem etnográfica na investigação científica. Revista Espaço, Rio de Janeiro, n. 16 jul-dez 2001. Disponível em: <http://www.ines.gov.br/paginas/revista/REVISTAS.htm>. Acesso em 21 mai. 2009.

MOREIRA, A. F. B. (org.). Currículo: questões atuais. Campinas: Papirus, 1997.

NEVES, Dulce Amélia. Ciência da informação e cognição humana: uma abordagem do processamento da informação. Ciência da Informação. Brasília, v. 35, n. 1, jan-abr, 2006, p. 39-44.

SANTAELLA, L. O que é semiótica. 3.ed. São Paulo: Brasiliense, 1985.

SANTAELLA, L. \& NÖTH, W. Imagem: cognição, semiótica, mídia. São Paulo: Ilumiruas, 2008.

SILVA, P. G. P. \& CAVASSAN, O. A influência da imagem estrangeira para o estudo da botânica no Ensino Fundamental. Revista Brasileira de Pesquisa em Educação em Ciências, v. 5, n. 1, jan/abr. 2005.

Sociedade Cientifica de Estudos da Arte, 2008. Disponível em <http://www.cesa.art.br/>. Acesso em: 15 fev. 2009. 
